\title{
MIT
}

\section{Polymer-Coated Mesoporous Carbon as Enzyme Platform for Oxidation of Bisphenol A in Organic Solvents}

The MIT Faculty has made this article openly available. Please share how this access benefits you. Your story matters.

\begin{tabular}{|l|l|}
\hline As Published & $10.1021 /$ ACSOMEGA.9B01945 \\
\hline Publisher & American Chemical Society (ACS) \\
\hline \hline Version & Final published version \\
\hline Citable link & https://hdl.handle.net/1721.1/132265 \\
\hline Terms of Use & $\begin{array}{l}\text { Article is made available in accordance with the publisher's } \\
\text { policy and may be subject to US copyright law. Please refer to the } \\
\text { publisher's site for terms of use. }\end{array}$ \\
\hline
\end{tabular}




\title{
Polymer-Coated Mesoporous Carbon as Enzyme Platform for Oxidation of Bisphenol A in Organic Solvents
}

\author{
Lidong $\mathrm{Wu},{ }^{\dagger, \ddagger \odot}$ Xiang Ji, ${ }^{\S}$ and Jing Kong*, ${ }^{*} \odot$ \\ ${ }^{\dagger}$ Key Laboratory of Control of Quality and Safety for Aquatic Products, Ministry of Agriculture, Chinese Academy of Fishery \\ Sciences, Beijing 100141, China \\ ${ }^{\ddagger}$ Department of Chemistry and ${ }^{\S}$ Department of Research Laboratory of Electronics, Massachusetts Institute of Technology, \\ Cambridge, Massachusetts 02139, United States
}

\section{Supporting Information}

ABSTRACT: Bisphenol A (BPA) is not only a widely used chemical but also a toxic pollutant, and its biodegradation in an aqueous environment is hard due to its near insolubility in water. While the enzyme tyrosinase can oxidize BPA in organic solvents, it does so only very slowly. In the present study, we have found that in toluene the catalytic activity of tyrosinase deposited onto coated mesoporous carbon is significantly enhanced when the support is precoated with polyethylenimine. The resultant enzymatically formed $o$-quinone is both easily recoverable and potentially useful monomer. As a particular example, the $o$-quinone readily reacts with diamine in toluene to form poly(amino-quinone) polymers, which are suitable for anticorrosion, energy storage, or biosensor applications.

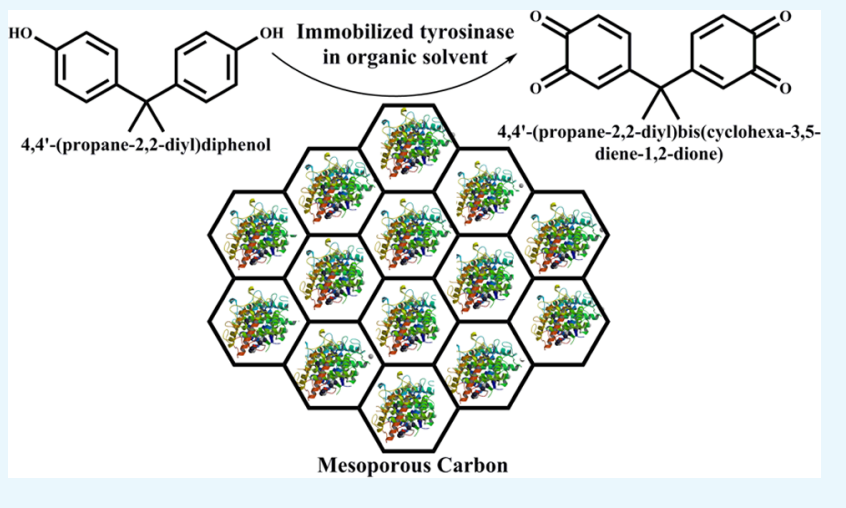

\section{INTRODUCTION}

Bisphenol A (BPA; Scheme 2) is one of the highest volume industrial chemicals used as a starting material to produce polycarbonate and epoxy resins. ${ }^{1}$ However, BPA is identified as a xenoestrogen; as a result, in 2012, it was banned in the United States for use in baby bottles due to its reproductive and developmental toxicity. ${ }^{2,3}$ Therefore, it is desirable to convert it into $o$-quinones, which easily react with nucleophiles to form polymers for anticorrosion, ${ }^{4}$ energy storage, ${ }^{5-7}$ and biosensor ${ }^{8,9}$ and so on. In previous efforts, Fremy's salt was used for the oxidation of phenolic compounds. ${ }^{10}$ However, this salt is unstable, releases flammable gases, and oxidizes extensively aromatic amines and phenols into quinones unselectively. Regio- and chemoselective oxidations of BPA under mild conditions have been a longstanding research goal. $^{11}$

The enzyme tyrosinase (also called polyphenol oxidase; EC 1.14.18.1) may overcome these challenges and be a good candidate for regio- and chemoselective oxidations of BPA under mild condition. Tyrosinase catalyzes the hydroxylation of phenols to catechols and subsequent dehydrogenation to $o$ quinones. ${ }^{12}$ Dopamine and L-tyrosine are easily oxidized by oxygen under tyrosinase catalysis in aqueous solution. BPA has poor solubility in water but is readily soluble in an organic solvent; ${ }^{13}$ for example, it is over an order of magnitude more soluble in toluene than in water. ${ }^{14-16}$ Meanwhile, there is an extra benefit that the cosubstrate oxygen has nearly 40 -fold higher solubility in toluene than in water. ${ }^{15}$ While we have used tyrosinase deposited onto glass beads to catalyze the oxidation of various phenols in organic solvents, the resultant enzymatic activity toward BPA is negligible, in part due to a low available surface area, which severely restricts the loading capacity of the carrier. ${ }^{17}$ Therefore, in this study, we have explored mesoporous carbon (MC) as immobilization support to enhance tyrosinase activity toward BPA in organic solvents.

The mesoporous carbon substrate has large surface area, high pore volume, and well-controlled pore size distribution allowing for high loading efficiency of the tyrosinase. Furthermore, it is a stable platform with high corrosion resistance and good thermal and mechanical properties. However, there is a certain degree of the conformational change of enzyme during the enzyme adsorption onto the carbon materials, which resulted in the loss of biological activity. ${ }^{18}$ The combination of polymers with mesoporous carbon might change its surface properties and create a biocompatible nanocomposite. In this work, several types of polymers are used for coating the surface of mesoporous carbon. Compared with the bare carrier, polyethylenimine (PEI)-coated mesoporous carbon as a tyrosinase immobilization platform improves over an order of magnitude higher enzymatic activity than just the mesoporous carbon. BPA is successfully converted into 4,4'-(1-methylethylidene)bis(1,2benzoquinone), which could be used as a monomer to react

Received: June 28, 2019

Accepted: September 11, 2019

Published: September 27, 2019 

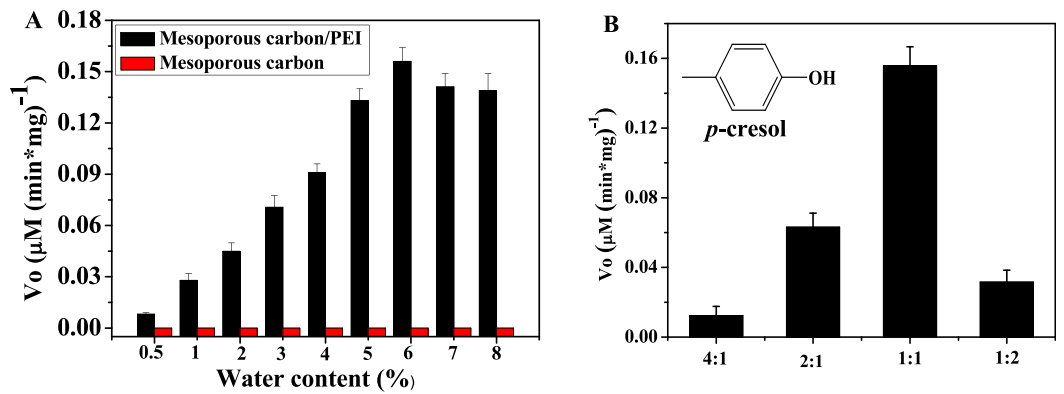

Figure 1. (A) $V_{\mathrm{o}}$ values of tyrosinase immobilized on mesoporous carbon and PEI-coated mesoporous carbon (the weight ratio of mesoporous carbon/PEI is 1:1) with different water contents. (B) $V_{\mathrm{o}}$ values of tyrosinase immobilization onto PEI/mesoporous carbon (the weight ratio mesoporous carbon/PEI are 4:1, 2:1, 1:1, and 1:2, respectively) catalyzed oxidations of $p$-cresol as substrate in toluene. $p$-Cresol concentration for these reactions is $50 \mathrm{mmol} \mathrm{L}{ }^{-1}$. Error bar means standard deviation. $V_{\mathrm{o}}$ is the amount of the oxidation product increased per min and per mg immobilized enzyme, measured by the absorption spectra. Inset: chemical structure of $p$-cresol.
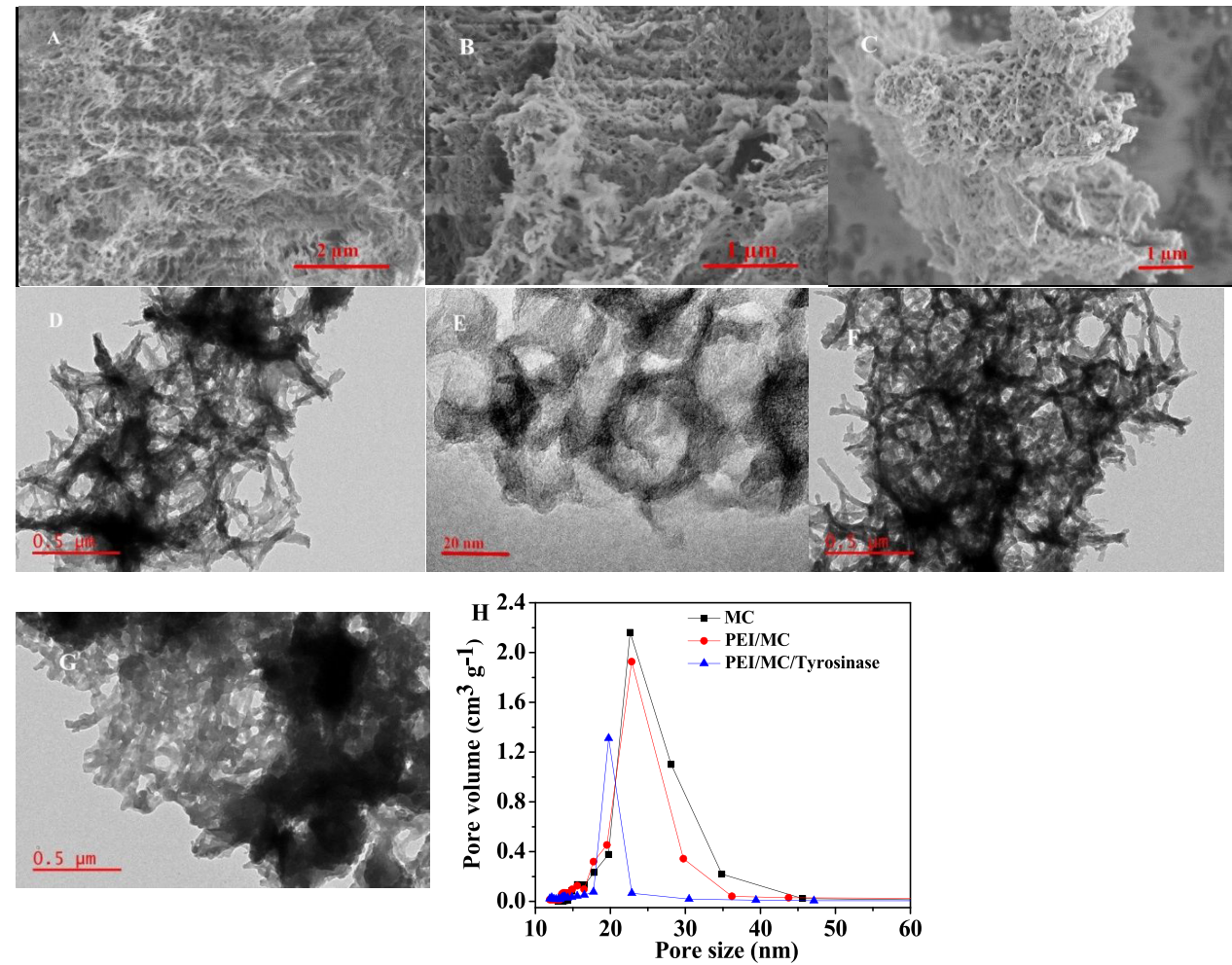

Figure 2. SEM images of (A) mesoporous carbon (MC), (B) mesoporous carbon with PEI, and (C) mesoporous carbon with PEI and tyrosinase. TEM images of (D) mesoporous carbon, (E) enlarged mesoporous carbon, (F) mesoporous carbon with PEI, and (G) mesoporous carbon with PEI and tyrosinase. $(\mathrm{H})$ The corresponding Barrett-Joyner-Halenda (BJH) pore size distribution of $\mathrm{MC}, \mathrm{PEI} / \mathrm{MC}$, and PEI/MC with tyrosinase.

with diamine to form poly(amino-quinone) polymers for applications in anticorrosion, energy storage, and biosensors.

\section{RESULTS AND DISCUSSION}

\subsection{Effects of the Immobilization Material on the} Tyrosinase Biocatalysis Ability. To study the tyrosinase catalysis in an organic solvent, we initially employed $p$-cresol as a model substrate, which is more easily oxidized than BPA. ${ }^{19}$ Its chemical structure is much simpler than BPA, as shown in the inset of Figure 1B. We investigated the tyrosinase-catalyzed oxidation reaction by monitoring the oxidation product of $p$ cresol. No significant formation of the enzymatic oxidation product was detected with $10 \mathrm{mg} \mathrm{mL}{ }^{-1}$ free tyrosinase suspended in toluene. It is likely due to the decreased conformational mobility of the enzyme structure and the free form of tyrosinase inactivation in an organic solvent. ${ }^{20}$ The use of immobilized enzyme instead of free form represents the most common method for improving enzyme stability toward organic solvents. The immobilized enzyme has more rigid conformation, which prevents unfolding of the enzyme and malformation of its active site. ${ }^{21}$ First, we precipitated the tyrosinase onto the glass beads. The enzymatic oxidation rate (defined as $V_{\mathrm{o}}$ ) is the amount of the oxidation product increased per min and per mg immobilized enzyme (measured by absorption spectra). The UV-vis instrument can accurately measure the enzymatic oxidation rate $\left(V_{\mathrm{o}}\right)$ of up to $0.001 \mu \mathrm{M}$ $\mathrm{min}^{-1} \mathrm{mg}^{-1}$. The enzymatic oxidation rate of the immobilized tyrosinase on glass beads was $0.02 \mu \mathrm{M} \mathrm{min}^{-1} \mathrm{mg}^{-1}$ for $p$-cresol with $6 \%$ water in toluene but not detectable for BPA even with over $6 \%$ water in toluene. The limited surface area (around $0.24 \mathrm{~m}^{2} \mathrm{~g}^{-1}$ ) of glass beads might result in a low loading efficiency of the tyrosinase. 
Table 1. Oxidation of $p$-Cresol by Tyrosinase Immobilized on Mesoporous Carbon or Coated Mesoporous Carbon

\begin{tabular}{|c|c|c|}
\hline Coating material & Property of coating material & $\begin{array}{l}\text { Oxidation rate of } p \text {-cresol } \\
\qquad\left(\mu \mathrm{M} \min ^{-1} \mathrm{mg}^{-1}\right)\end{array}$ \\
\hline $\begin{array}{l}\text { Polyethylenimine } \\
\text { (PEI) }\end{array}$ & & $0.156 \pm 0.008$ \\
\hline $\begin{array}{l}\text { Polyethylene glycol } \\
\qquad \text { (PEG) }\end{array}$ & & 0 \\
\hline Polyacrylate (PAL) & & $0.089 \pm 0.012$ \\
\hline DEAE-cellulose & & $0.092 \pm 0.009$ \\
\hline Cellulose & $\left.\int_{\mathrm{OH}}^{\mathrm{T}}\right]_{\mathrm{n}}$ & $0.086 \pm 0.006$ \\
\hline CM-cellulose & $\left(\int_{\mathrm{OR}}^{\mathrm{O}}\right)_{\mathrm{n}} \mathrm{R}=\mathrm{CH}_{2} \mathrm{CO}_{2} \mathrm{H}$ & $0.037 \pm 0.007$ \\
\hline Lysozyme & 20 & $0.062 \pm 0.005$ \\
\hline Bovine serum albumin & 3. & $0.054 \pm 0.007$ \\
\hline
\end{tabular}

Mesoporous carbon was chosen as a support to immobilize the tyrosinase due to its large surface area $\left(500-1000 \mathrm{~m}^{2}\right.$ $\left.\mathrm{g}^{-1}\right) .2$ In this experiment, the specific surface area of mesoporous carbon was $582 \mathrm{~m}^{2} \mathrm{~g}^{-1}$. When $5 \mathrm{mg} \mathrm{mL}^{-1}$ mesoporous carbon was mixed with $50 \mathrm{mmol} \mathrm{L}^{-1} p$-cresol or $0.2 \mathrm{mmol} \mathrm{L}{ }^{-1} \mathrm{BPA}$ in aqueous solution, it was found through UV-vis measurements that over $90 \% \mathrm{BPA}$ and $p$-cresol were adsorbed from aqueous solution to mesoporous carbon. However, compared with aqueous solution, less than $5 \%$ $\mathrm{BPA}$ and $p$-cresol were adsorbed from toluene to mesoporous carbon; this makes the detection of BPA reactions easier. However, Figure $1 \mathrm{~A}$ indicates that the reaction product was still not detectable even when $8 \%$ of water was added to the toluene. During the adsorption process, it is possible that a certain degree of conformational change in the tyrosinase resulted in the loss of biological activity. ${ }^{\text {is }}$

Our experiments show that only mesoporous carbon is not readily biocompatible. Coating polymers onto carbon materials could change its surface properties and create a biocompatible nanocomposite. ${ }^{23,24}$ Polyethylenimine (PEI), a cationic polymer, is used in encapsulating protein antigen and DNA via electrostatic attraction. ${ }^{25,26}$ After PEI was identified as the potential candidate of the coating material, from 1 to $8 \%$ of water was added to the toluene to test the immobilized tyrosinase activity. Adequate water content in the reaction medium is crucial. ${ }^{27}$ As shown in Figure 1A, higher water percentages led to greater rates of enzymatic oxidation. However, after adding $6 \%$ water, the rate of enzymatic oxidation leveled off and decreased slightly. After optimizing the water content, the weight ratio between PEI and mesoporous carbon as an enzyme immobilization platform was then investigated. The rate of enzymatic oxidation increased until the weight ratio was 1:1 (PEI/mesopourous carbon) and then decreased with a 2:1 ratio (Figure 1B).
Therefore, the optimized condition includes a $1: 1 \mathrm{PEI} /$ mesoporous carbon weight ratio for the immobilization platform with $6 \%$ of water in the reaction medium.

2.2. Physical Characterization of PEI/Mesoporous Carbon and Tyrosinase Immobilization onto PEI/ Mesoporous Carbon. The surface of the PEI-coated mesoporous carbon was characterized by scanning electron microscopy (SEM), transmission electron microscopy (TEM), and nitrogen adsorption-desorption isotherms. Figure $2 \mathrm{~A}$ demonstrates the ordered pore morphology of unmodified mesoporous carbon. After PEI was coated onto the mesoporous carbon (Figure $2 \mathrm{~B}$ ), the surface appeared rougher. This alteration supports the conclusion that the PEI had been coated onto the surface of the mesoporous carbon. Figure $2 \mathrm{C}$ shows the SEM image of the samples after immobilization of tyrosinase onto the PEI/mesoporous carbon. The TEM images were used for confirming the SEM results. Figure 2D,E (the enlarged view) shows uniformly distributed spherical pores of mesoporous carbon, and its edge is very clear. After PEI was coated onto the mesoporous carbon (Figure $2 \mathrm{~F}$ ), the edge of the nanocomposite appears rougher. Subsequently, after immobilization of tyrosinase onto the $\mathrm{PEI} /$ mesoporous carbon (Figure $2 \mathrm{G}$ ), its edges become even rougher than the bare nanocomposite.

Figure $2 \mathrm{H}$ shows the pore size distribution for mesoporous carbon and the nanocomposite by the Barrett-JoynerHalenda (BJH) method. The average pore size of mesoporous carbon is $22 \mathrm{~nm}$ with a specific surface area and pore volume of $582 \mathrm{~m}^{2} \mathrm{~g}^{-1}$ and $2.1 \mathrm{~cm}^{3} \mathrm{~g}^{-1}$, respectively. After coating PEI on the mesoporous carbon surface, the pore size remains unchanged, while the surface area and pore volume decreased to $505 \mathrm{~m}^{2} \mathrm{~g}^{-1}$ and $1.9 \mathrm{~cm}^{3} \mathrm{~g}^{-1}$, respectively. This suggests that the mesoporous carbon had been coated by PEI, which slightly reduced the surface area and pore volume. After tyrosinase 
Scheme 1. Process of PEI Coating Mesoporous Carbon To Immobilize Tyrosinase (A) PEI Coating Mesoporous Carbon To Immobilize Tyrosinase, (B) PEG Coating Mesoporous Carbon To Immobilize Tyrosinase, (C) PAL Coating Mesoporous Carbon To Immobilize Tyrosinase; ${ }^{a}$ Photographs of the Powder of (D) PEI Coating Mesoporous Carbon, (E) PEG Coating Mesoporous Carbon, and (F) PAL Coating Mesoporous Carbon
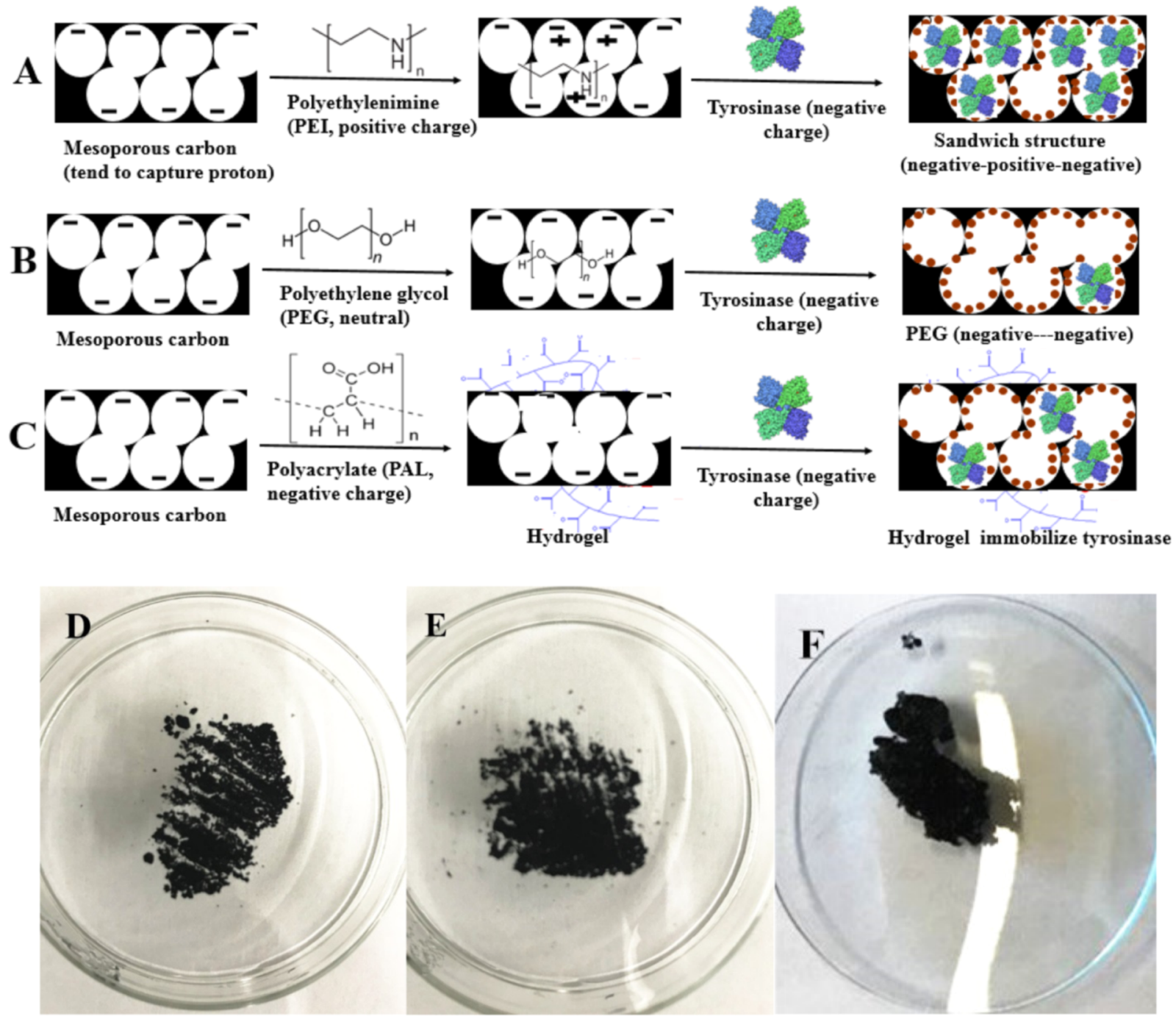

${ }^{a}$ The brown dots represent the coating materials in the scheme.

immobilization onto the PEI-coated mesoporous carbon surface, its surface area and pore volume further decreased to $200 \mathrm{~m}^{2} \mathrm{~g}^{-1}$ and $1.3 \mathrm{~cm}^{3} \mathrm{~g}^{-1}$, respectively, indicating that the tyrosinase had been immobilized onto the surface of coated mesoporous carbon.

2.3. Coating Materials Influence the Immobilized Tyrosinase Biocatalysis Ability. To understand the role played by the PEI coating, several different polymers were also used as coating materials. Table 1 shows that the rates of enzymatic oxidation after tyrosinase immobilization onto poly(ethylene glycol) (PEG)-coated mesoporous carbon, polyacrylate (PAL)-coated mesoporous carbon, diethylaminoethyl-cellulose (DEAE-cellulose)-coated mesoporous carbon, cellulose-coated mesoporous carbon, carboxymethylcellulose (CM-cellulose)-coated mesoporous carbon, bovine serum albumin (BSA)-coated mesoporous carbon, and lysozyme-coated mesoporous carbon were 0, 0.089, 0.092, $0.086,0.037,0.062$, and $0.054 \mu \mathrm{M} \mathrm{min}^{-1} \mathrm{mg}^{-1}$, respectively.
The relative deviation numbers indicated that the reproducibility of the experimental procedure was reliable.

e divided the coating material into three groups for a
better understanding. The three traditional polymers can be categorized based on the charges on their surface: PEI (positive charge), PEG (neutral), and PAL (negative charge). Table 1 shows that the rate of enzymatic oxidation after tyrosinase immobilization was highest for the PEI-coated mesoporous carbon. The electrostatic attractions likely assist the coating of the positively charged PEI onto the negatively charged mesoporous carbon. The abundant amine groups on PEI (where the positive charges are from) could also electrostatically attract the negative charges of tyrosinase (as shown in Scheme 1). In this way, high catalytic efficiency of the immobilized tyrosinase could be achieved. PAL, an anionic polymer with negatively charged carboxylic groups in the main chain, had the next highest rate of oxidation. Even though PAL is a negatively charged polymer, previous studies have found that PAL can bind with mesoporous carbon to form a 
Table 2. Comparison of the Oxidation BPA by Enzyme Biocatalysis Method with Other Oxidation Methods

\begin{tabular}{|c|c|c|c|c|c|}
\hline oxidation method & selectivity & efficiency & reaction rate $\left(\mathrm{mol} \mathrm{min}^{-1}\right)$ & safety & ref \\
\hline ozone oxidation & low & mediate & $2.34 \times 10^{-6}$ & respiratory illness & 44,45 \\
\hline chemical oxidation & mediate & mediate & $0.72 \times 10^{-6}$ & easy explosion & 46,47 \\
\hline electrochemical oxidation & mediate & low & $2 \times 10^{-9}$ & safe & 48 \\
\hline photocatalytic oxidation & mediate & mediate & $7.8 \times 10^{-6}$ & safe & 49 \\
\hline tyrosinase oxidation & high & high & $39 \times 10^{-6}$ & very safe & present work \\
\hline
\end{tabular}
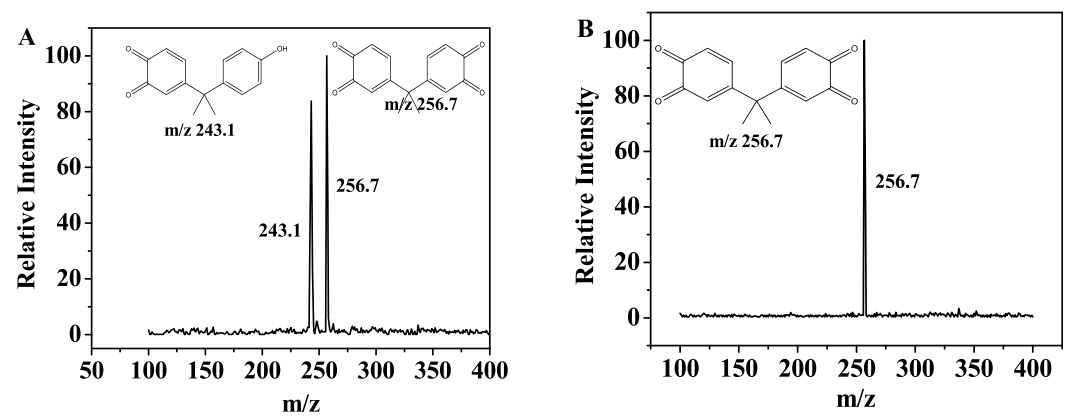

Figure 3. High-performance liquid chromatography-MS analysis of BPA product after mixing with the immobilized tyrosinase for 60 min in toluene with a $6 \%$ water content (A) and for $10 \mathrm{~h}$ in toluene with a $6 \%$ water content (B).

hydrogel $^{28-30}$ through hydrogen bonding. The photograph of Scheme $1 \mathrm{~F}$ also verified this. The retained water in the hydrogel could be beneficial for keeping the enzymatic activity of tyrosinase. However, there was electrostatic repulsion between PAL and the tyrosinase, ${ }^{31}$ limiting its catalytic efficiency. In the case of PEG, which is a neutral polymer, it was found that the catalytic efficiency of the immobilized tyrosinase was undetectable after PEG coating onto the mesoporous carbon. The PEG coating did not improve the catalytic efficiency of the immobilized tyrosinase, possibly due to the fact that there was not enough tyrosinase loaded onto the surface, as PEG was used to as a steric barrier for avoiding proteins sticking onto the surface of the materials in the previous research. ${ }^{32,33}$

The second polymer coating group consists of three differently charged cellulose, and their chemical structures are shown in Table 1 . Table 1 also shows that the rate of enzymatic oxidation after tyrosinase immobilization was highest for the positively charged DEAE-cellulose, corroborating the results from the first polymer screening. The negatively charged CM-cellulose-coated mesoporous carbon had the lowest activity among the cellulose coatings, possibly due to electrostatic repulsion. ${ }^{34}$ Neutral cellulose-coated mesoporous carbon had similar activity to PAL, likely due to its ample hydroxyl groups, which could create a similar hydrogenbonding network to maintain the catalytic efficiency of the immobilized tyrosinase. ${ }^{35}$ These results indicate that electrostatic attraction plays an important role in immobilizing tyrosinase, while other factors, such as hydrogen bonding or steric barrier, are also vital for immobilization efficiency.

In addition to using synthetic polymers as coating materials, we also used proteins to coat mesoporous carbon as previous reports showed that protein coatings could provide a biocompatible surface for immobilizing enzymes. ${ }^{36,37}$ Two common proteins, lysozyme and bovine serum albumin (BSA), were selected for coatings on the surface of mesoporous carbon. Table 1 shows that the rates of enzymatic oxidation were similar for both lysozyme and BSA. Lysozyme (molecular weight: $14.3 \mathrm{kDa}$ ) is thermally stable and its isoelectric point is $11.35{ }^{38}$ Thus, lysozyme likely played a similar role as PEI in creating a layer-by-layer structure of negative and positive charges. BSA (molecular weight: $66.5 \mathrm{kDa}$ ) is a serum albumin protein and its isoelectric point is $4.7 .^{39}$ It is possible that the positively charged residues on the BSA surface interacted with the surface of mesoporous carbon, allowing the BSA to be stably adsorbed. ${ }^{40}$ As both BSA and lysozyme could be coated onto mesoporous carbon by a positively charged subdomain, their ample hydroxyl and amino groups could create a hydrogen-bonding network to maintain the catalytic efficiency of the immobilized tyrosinase. The oxidation rates of lysozymecoated mesoporous carbon had a slightly higher activity than those of BSA-coated mesoporous carbon. These results corroborate that electrostatic attraction plays the main role in immobilizing tyrosinase.

2.4. Oxidation of BPA Using the Immobilized Tyrosinase. After optimizing the experimental conditions with $p$-cresol, the tyrosinase immobilization onto PEI/ mesoporous carbon was used as a biocatalyst for the oxidation of BPA in toluene. The rate of enzymatic oxidation for BPA $\left(10 \mathrm{mmol} \mathrm{L}^{-1}\right)$ in toluene with $6 \%$ water was $0.039 \mu \mathrm{M} \mathrm{min}^{-1}$ $\mathrm{mg}^{-1}$. The rate of enzymatic oxidation for BPA is lower than that for $p$-cresol due to its stronger steric hindrance. Furthermore, the rates of enzymatic oxidation for BPA (10 $\mathrm{mmol} \mathrm{L}{ }^{-1}$ ) in chloroform, acetone, ethanol, and methanol with $6 \%$ water were $0.021,0,0$, and $0 \mu \mathrm{M} \mathrm{min}^{-1} \mathrm{mg}^{-1}$, respectively. As shown in Table 2, compared with the ozone oxidation of BPA, chemical oxidation of BPA, photocatalytic oxidation of $\mathrm{BPA}$, and electrochemical oxidation of BPA, the enzyme oxidation of BPA shows both high selectivity and almost an order of magnitude higher efficiency. More importantly, tyrosinase oxidation of BPA is the safest method among all of them. After $60 \mathrm{~min}$ of reaction with the immobilized tyrosinase, BPA was converted into 4-[1-(4-hydroxyphenyl)-1methyl-ethyl]-1,2-benzoquinone and 4,4'-(1methylethylidene)bis(1,2-benzoquinone) (o-quinone product) as oxidation products determined by liquid chromatographymass spectrometry (LC-MS) (Figure 3). The ratio between the two products was approximately $1: 1$ (Figure $3 \mathrm{~A}$ ). After 10 $\mathrm{h}$ of reaction, the mass spectrometry results showed that all of the oxidation product was the $o$-quinone product (Figure 3B). 
Furthermore, NMR has been tested for BPA and bisquinone (Figure S1). In the ${ }^{1} \mathrm{H}$ NMR spectrum of the bisquinone $\left[{ }^{1} \mathrm{H}\right.$ NMR, $6.44(2 \mathrm{H}, \mathrm{dd}, J=10.3$ and $0.7 \mathrm{~Hz}, \mathrm{H} 6), 6.48(2 \mathrm{H}, \mathrm{dd}, J$ $=2.4$ and $0.7 \mathrm{~Hz}, \mathrm{H} 3), 6.65(2 \mathrm{H}, \mathrm{dd}, J=10.3$ and $2.4 \mathrm{~Hz}$, $\mathrm{H} 5)$ ], the signals of 4-substituted phenol were not observed, but only signals of a 1,2-quinone moiety and a singlet methyl group were observed. Together with the data of the highresolution mass measurement, this compound was identified as the bisquinone derivative of bisphenol A.

The reaction mechanism is shown in Scheme 2. The oquinone product is stable in toluene solution as a monomer; in

Scheme 2. Possible Reaction Pathways for Bisphenol A Oxidation by Immobilized Tyrosinase under Oxygen

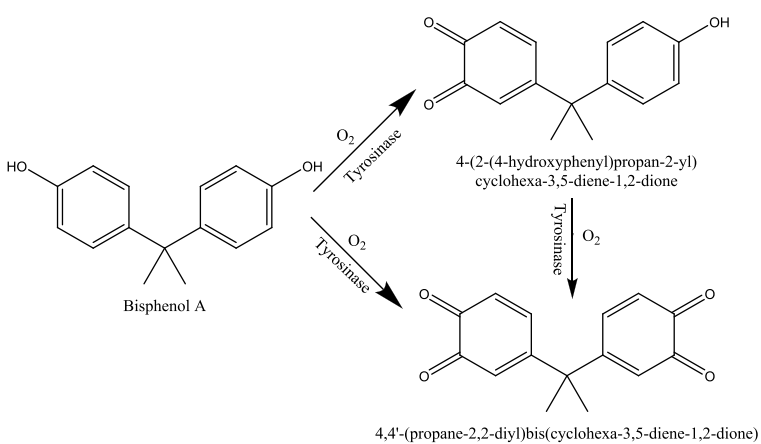

contrast, it is prone to aggregation in aqueous solution. ${ }^{41}$ Therefore, this strategy of converting BPA in toluene solution to $o$-quinone will allow controllable polymerization and potentially can be very useful for future applications.

This o-quinone product has four carbonyl groups, which may further react with a variety of nucleophiles in various pathways. Well-known nucleophiles, such as amines, may react with the $o$-quinone to form adducts either by the Michael addition or Schiff base reactions, as shown in Scheme 3. Therefore, in this study, we used 4,4'-(1-methylethylidene)bis(1,2-benzoquinone) and hexamethylenediamine to study the cross-linking chemistry, and the reaction mechanism is shown in Figure 4D. After adding hexamethylenediamine into 4,4'-(1-methylethylidene) bis(1,2-benzoquinone) in toluene, the color changed from yellow to purple (Figure 4C), indicating that a reaction had taken place, and the poly(amino-quinone) with a honeycomb-like nanostructure was formed (as shown in Figure 4A). Figure 4B shows the SEM image of the polymer showing lots of nanopores on the surface of this polymer, resulting in a rough surface. Figure 5A shows the branched polymer formed when trilysine, a short peptide with an amino group, reacted with 4,4'-(1-methylethylidene)bis (1,2-benzoquinone) in toluene (the reaction mechanism is shown in Figure 5B). In this way, the 4,4'-(1methylethylidene)bis(1,2-benzoquinone) serves as another condensing reagent like the commonly used carbodiimide reagents (1-ethyl-3-(3-dimethylaminopropyl)carbodiimide hy-

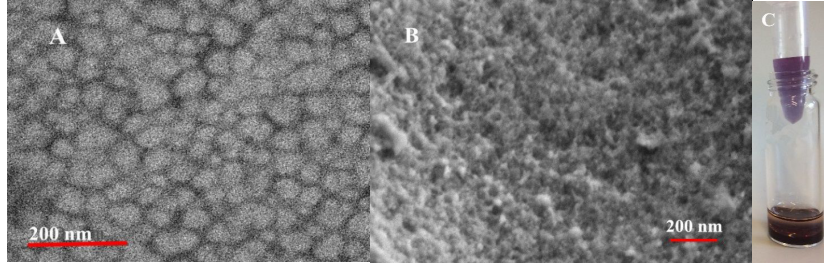

D

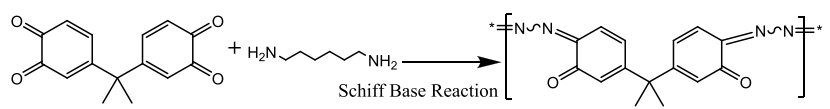

Figure 4. TEM image of poly(amino-quinone) polymers formed by hexamethylenediamine and 4,4'-(1-methylethylidene)bis(1,2-benzoquinone) (A), SEM images of this polymer (B), the photograph of the reaction product poly(amino-quinone) polymers, the dilution of poly(amino-quinone) polymers in the upper vial, and the poly(aminoquinone) polymers deposited on the bottom of glass bottle (C), and the reaction of hexamethylenediamine with 4,4'-(propane-2,2-diyl)bis(cyclohexa-3,5-diene-1,2-dione) through the Schiff base reaction (D).

drochloride). Because it has quinone groups on both sides, it can covalently bind to amino-functionalized surfaces on one side and bind to peptides (enzymes) on the other side; thus, it can be used for anchoring peptides on surfaces conveniently. Scheme 4 shows an example with the commonly used sepharose particle as an anchoring substrate. This bisquinone enriches the immobilization method for proteins or peptides as bifunctional reagents. Furthermore, polymers with quinone groups can easily adhere to metals and alloys ${ }^{4,42}$ and can be used for anticorrosion application, as well.

\section{CONCLUSIONS}

This work developed a method to selectively oxidize BPA under mild conditions. The model enzyme (tyrosinase) was directly immobilized onto the surface of mesoporous carbon via physical adsorption ability. The rate of enzymatic oxidation was improved by coating the mesoporous carbon with various polymers. Among these coating materials, PEI resulted in the highest rate of oxidation due to its ability to form a charge sandwich structure to protect tyrosinase. The final oxidation product of BPA is 4,4'-(1-methylethylidene)bis(1,2-benzoquinone), which can be used as a monomer to form the poly(amino-quinone) polymers by the Schiff base reactions. It can be anticipated that potentially it could be used as a BPA replacement in many of current applications. This research also develops an effective coating strategy, which can make mesoporous carbon a promising immobilization platform for applications in biocatalysis, biosensing, and drug delivery and will facilitate the development of high-catalytic-efficiency enzyme bioelectronic devices and biofuel battery.

Scheme 3. Reaction of Amines with 4,4' -(Propane-2,2-diyl)bis(cyclohexa-3,5-diene-1,2-dione) via the Michael-Type Addition or Schiff Base Reaction

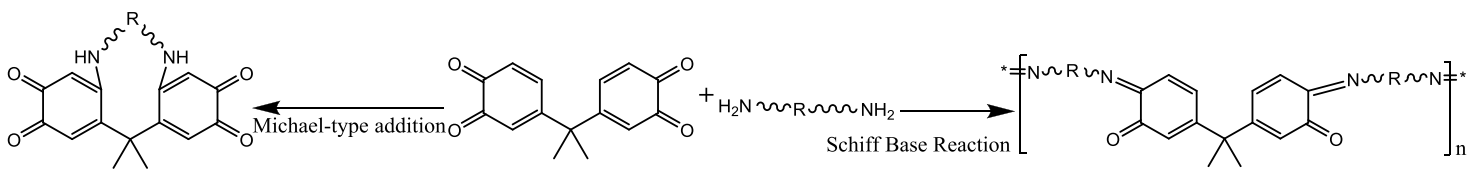




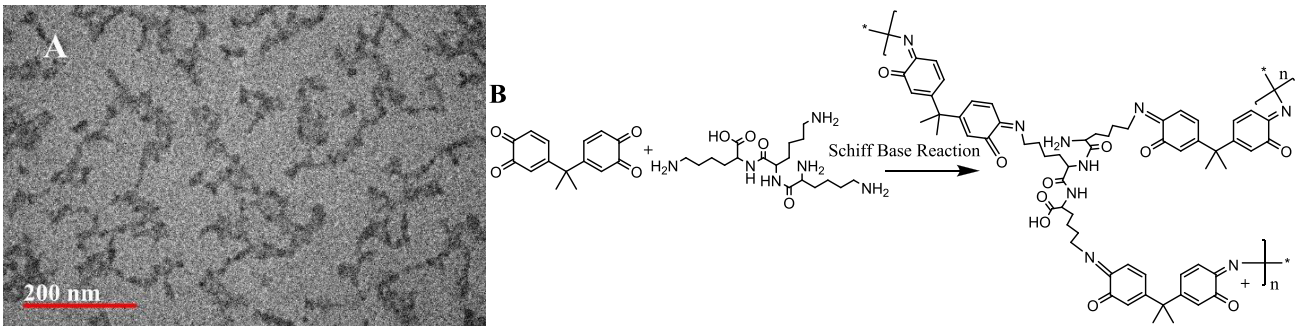

Figure 5. TEM image of poly(amino-quinone) polymers formed by trilysine and 4,4'-(1-methylethylidene)bis(1,2-benzoquinone) (A) and the reaction mechanism of trilysine and $4,4^{\prime}$-(1-methylethylidene)bis(1,2-benzoquinone) (B).

Scheme 4. 4,4' -(Propane-2,2-diyl)bis(cyclohexa-3,5-diene-1,2-dione) Reaction with Amine-Modified Sepharose Particle and Protein with $\mathrm{NH}_{2}$ via the Schiff Base Reaction

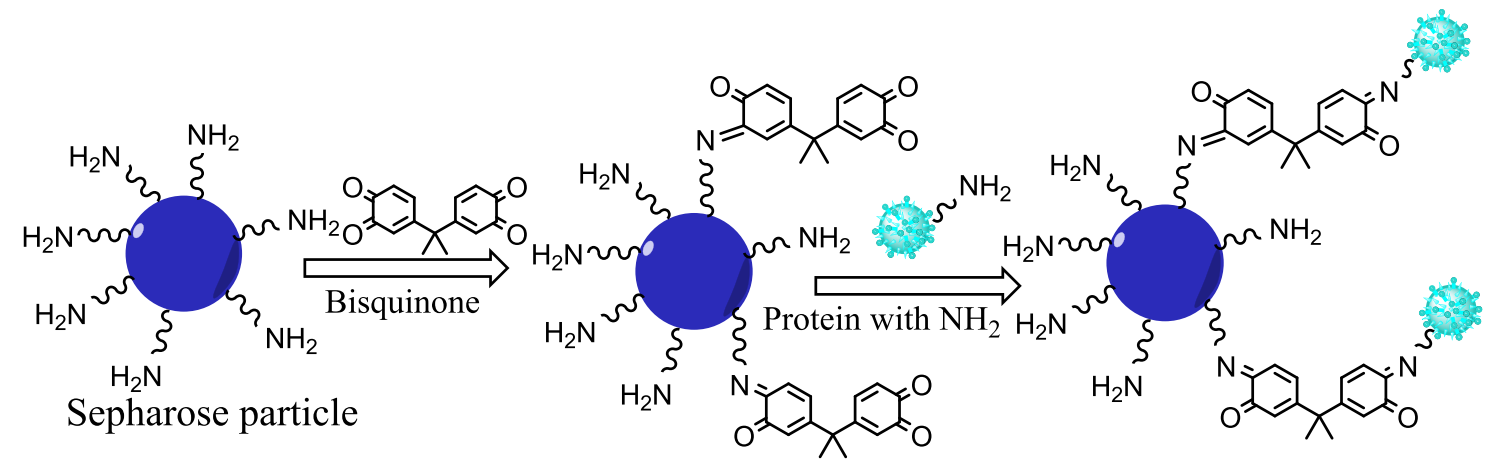

\section{EXPERIMENTAL SECTION}

4.1. Materials. BPA, para-cresol ( $p$-cresol), and other chemicals were obtained from Sigma-Aldrich, and their purity was higher than $99 \%$. Mushroom tyrosinase $(50 \mathrm{kU})$ was from Sigma-Aldrich as a solid with a specific activity of 2430 unit $\mathrm{mg}^{-1}$ ( 1 unit is defined as the enzyme activity resulting in an increase in absorbance at $280 \mathrm{~nm}$ of 0.001 at $\mathrm{pH} 6.5$ at $25{ }^{\circ} \mathrm{C}$ in a $3 \mathrm{~mL}$ reaction solution containing L-tyrosine). Polyethylenimine (PEI, $M_{\mathrm{n}}$ 1200), poly(ethylene glycol) (PEG, $\left.M_{\mathrm{n}} 1500\right)$, polyacrylate (PAL, $M_{\mathrm{n}}$ 1250), diethylaminoethyl-cellulose (DEAE-cellulose, microgranular), carboxymethyl-cellulose (CM-cellulose, microgranular), cellulose (fiber), hen egg-white lysozyme $\left(M_{\mathrm{w}}: 14.4 \mathrm{kDa}\right)$, and bovine serum albumin (BSA, $M_{\mathrm{w}}: 66 \mathrm{kDa}$ ) were also from SigmaAldrich.

4.2. Instrumentations. Scanning electron microscope images were obtained by a high-resolution SEM (Zeiss Merlin, Germany) with a resolution of $0.8 \mathrm{~nm}$ at $15 \mathrm{kV}$ and $1.4 \mathrm{~nm}$ at 1 $\mathrm{kV}$. Transmission electron microscope images were obtained from an FEI Tecnai multipurpose TEM (ThermoFisher Scientific). Nitrogen adsorption-desorption isotherms were obtained using a Micromeritics ASAP 2010 apparatus. Liquid chromatography-mass spectrometry (LC-MS, Agilent 6000 series) was used to monitor the mass of the product. Absorption spectroscopy was detected by a UV-vis spectrophotometry (TheromFisher nanodrop 2000c).

4.3. Preparation of PEI/Mesoporous Carbon Nanocomposite and Immobilization of Tyrosinase. Mesoporous carbon was synthesized using $22 \mathrm{~nm}$ silica nanospheres as template. The synthesis of monodisperse silica nanospheres $(22 \mathrm{~nm})$ was based on the so-called "Stober method" reported by our previous method. ${ }^{43}$ In short, tetraethoxysilane, L-lysine, and $\mathrm{H}_{2} \mathrm{O}$ were mixed together with a weight ratio of 1:0.01:78. The above-mixed solution was stirred for $12 \mathrm{~h}$ under $80{ }^{\circ} \mathrm{C}$ to obtain $22 \mathrm{~nm}$ silica nanospheres. Mesoporous carbon was synthesized using the obtained $22 \mathrm{~nm}$ silica nanospheres as template according to our previously reported procedure. ${ }^{43}$ The procedure was as follows: $1.0 \mathrm{~g}$ dried silica spheres were impregnated with a $0.5 \mathrm{mM} \mathrm{Ni}\left(\mathrm{NO}_{3}\right)_{2} \cdot 6 \mathrm{H}_{2} \mathrm{O}$ aqueous solution and then dried at $45{ }^{\circ} \mathrm{C}$. After being ground in an agate mortar, these silica particles were pressed into pellets. Then, silica pellets were immersed into the preliminarily polymerized polystyrene, followed by heating the composite at $160{ }^{\circ} \mathrm{C}$ for $24 \mathrm{~h}$ to allow the impregnation of polystyrene into the interstices of the silica template. Thereafter, the composite was allowed to undergo pyrolysis/carbonization at $950{ }^{\circ} \mathrm{C}$ for $3 \mathrm{~h}$ under a nitrogen atmosphere and cooled down to room temperature. The silica spheres were removed from the composite using a $20 \%$ hydrogen fluoride solution for $24 \mathrm{~h}$ and drying at $120{ }^{\circ} \mathrm{C}$ to yield the final graphitized ordered mesoporous carbon.

To form the PEI-coated mesoporous carbon, $20 \mathrm{~mL}$ of $5 \mathrm{mg}$ $\mathrm{mL}^{-1}$ mesoporous carbon was mixed with $20 \mathrm{~mL}$ of $5 \mathrm{mg}$ $\mathrm{mL}^{-1} \mathrm{PEI}$ and stirred at room temperature for $18 \mathrm{~h}$. Then the sediment was separated by centrifugation at $4500 \mathrm{rpm}$ for 25 min, washed with deionized water thrice, recovered by decantation, and dried at room temperature for $3 \mathrm{~h}$ to obtain the final $\mathrm{PEI} /$ mesoporous carbon nanocomposite.

Solid tyrosinase $(2 \mathrm{mg}$ ) was dissolved in $0.2 \mathrm{~mL}$ of $50 \mathrm{mmol}$ $\mathrm{L}^{-1}$ phosphate-buffered saline (PBS), $\mathrm{pH} 7.0$, and then $10 \mathrm{mg}$ of $\mathrm{PEI} /$ mesoporous carbon was added. The sticky mixture was spread on a watch glass and left to dry at room temperature for $2 \mathrm{~h}$. The tyrosinase immobilization onto other materials was prepared following a similar protocol.

4.4. Monitoring of Tyrosinase Activity. The time course for tyrosinase-catalyzed oxidation of $p$-cresol or BPA in organic solvents was monitored using a UV-vis Nanodrop 2000C spectrophotometer (ThermoFisher Scientific) using the following procedure. $p$-Cresol $\left(1 \mathrm{~mL}\right.$ of $\left.50 \mathrm{mmol} \mathrm{L}^{-1}\right)$ in an organic solvent was added into a $5 \mathrm{~mL}$ round-bottom flask, 
followed by the addition of $5 \mu \mathrm{L}$ of $50 \mathrm{mmol} \mathrm{L}^{-1} \mathrm{PBS}$ ( $\mathrm{pH} 7.0$ ) and $1 \mathrm{mg}$ of the immobilized tyrosinase, and the suspension was mixed using a magnetic stirrer at $250 \mathrm{rpm}$ and $25{ }^{\circ} \mathrm{C}$. Aliquots of the liquid were periodically withdrawn, and their absorption spectra were recorded in the range of $400-600 \mathrm{~nm}$.

\section{ASSOCIATED CONTENT}

\section{S Supporting Information}

The Supporting Information is available free of charge on the ACS Publications website at DOI: 10.1021/acsomega.9b01945.

NMR of BPA and bisquinone (Figure S1) (PDF)

\section{AUTHOR INFORMATION}

\section{Corresponding Author}

*E-mail: jingkong@mit.edu. Tel: +1-617-324-4068. Fax: +1617-324-5293.

\section{ORCID}

Lidong Wu: 0000-0002-6397-6516

Jing Kong: 0000-0003-0551-1208

\section{Notes}

The authors declare no competing financial interest.

\section{ACKNOWLEDGMENTS}

L.W. acknowledges the support by Central Public-interest Scientific Institution Basal Research Fund, CAFS (No. 2019ZD08). X.J. and J.K. acknowledge the support of HK ITC grant reference: ITS/195/14FP. The authors would like to thank Prof. Alexander M. Klibanov for many helpful suggestions in experiment details and Dr. Lisa Volpatti for help in revising the manuscript.

\section{REFERENCES}

(1) Le, H. H.; Carlson, E. M.; Chua, J. P.; Belcher, S. M. Bisphenol A is released from polycarbonate drinking bottles and mimics the neurotoxic actions of estrogen in developing cerebellar neurons. Toxicol. Lett. 2008, 176, 149-156.

(2) Patisaul, H. B.; Todd, K. L.; Mickens, J. A.; Adewale, H. B. Impact of neonatal exposure to the ER alpha agonist PPT, bisphenolA or phytoestrogens on hypothalamic kisspeptin fiber density in male and female rats. Neurotoxicology 2009, 30, 350-357.

(3) Gear, R. B.; Belcher, S. M. Impacts of Bisphenol A and Ethinyl Estradiol on Male and Female CD-1 Mouse Spleen. Sci. Rep. 2017, 7, No. 856.

(4) Chen, S.; Zhang, J.; Chen, Y.; Zhao, S.; Chen, M.; Li, X.; Maitz, M. F.; Wang, J.; Huang, N. Application Of Phenol/Amine Copolymerized Film Modified Magnesium Alloys: Anticorrosion And Surface Biofunctionalization. ACS Appl. Mater. Interfaces 2015, 7, 24510-24522.

(5) Pham, M. C.; Hubert, S.; Piro, B.; Maurel, F.; Le Dao, H.; Takenouti, H. Investigations of the redox process of conducting poly(2-methyl-5-amino-1,4-naphthoquinone) (PMANQ) film Interactions of quinone-amine in the polymer matrix. Synth. Met. 2004, 140, 183-197.

(6) Liang, Y. L.; Jing, Y.; Gheytani, S.; Lee, K. Y.; Liu, P.; Facchetti, A.; Yao, Y. Universal quinone electrodes for long cycle life aqueous rechargeable batteries. Nat. Mater. 2017, 16, 841-848.

(7) Navarro-Suárez, A. M.; Carretero-González, J.; Rojo, T.; Armand, M. Poly(quinone-amine)/nanocarbon composite electrodes with enhanced proton storage capacity. J. Mater. Chem. A 2017, 5, 23292-23298.

(8) Arai, G.; Shoji, K.; Yasumori, I. Electrochemical characteristics of glucose oxidase immobilized in poly(quinone) redox polymers. $J$. Electroanal. Chem. 2006, 591, 1-6.
(9) Martín, M.; Orive, A. G.; Lorenzo-Luis, P.; Creus, A. H.; González-Mora, J. L.; Salazar, P. Quinone-Rich Poly(dopamine) Magnetic Nanoparticles for Biosensor Applications. ChemPhysChem 2014, 15, 3742-3752.

(10) Hans, Z.; Lankin, D. C.; Horgan, S. W. Oxidations with potassium nitrosodisulfonate (Fremy's radical). Teuber reaction. Chem. Rev. 1970, 71, 229-247.

(11) Esguerra, K. V. N.; Lumb, J. P. Selectivity in the Aerobic Dearomatization of Phenols: Total Synthesis of Dehydronornuciferine by Chemo- and Regioselective Oxidation. Angew. Chem., Int. Ed. 2018, 57, 1514-1518.

(12) Hoffmann, A.; Citek, C.; Binder, S.; Goos, A.; Rubhausen, M.; Troeppner, O.; Ivanovic-Burmazovic, I.; Wasinger, E. C.; Stack, T. D. P.; Herres-Pawlis, S. Catalytic Phenol Hydroxylation with Dioxygen: Extension of the Tyrosinase Mechanism beyond the Protein Matrix. Angew. Chem., Int. Ed. 2013, 52, 5398-5401.

(13) Nicolucci, C.; Rossi, S.; Menale, C.; Godjevargova, T.; Ivanov, Y.; Bianco, M.; Mita, L.; Bencivenga, U.; Mita, D. G.; Diano, N. Biodegradation of bisphenols with immobilized laccase or tyrosinase on polyacrylonitrile beads. Biodegradation 2011, 22, 673-683.

(14) Battino, R.; Rettich, T. R.; Tominaga, T. The Solubility of Oxygen and Ozone in Liquids. J. Phys. Chem. Ref. Data 1983, 12, $163-178$.

(15) Sato, T.; Hamada, Y.; Sumikawa, M.; Araki, S.; Yamamoto, H. Solubility of Oxygen in Organic Solvents and Calculation of the Hansen Solubility Parameters of Oxygen. Ind. Eng. Chem. Res. 2014, 53, 19331-19337.

(16) Corrales, J.; Kristofco, L. A.; Steele, W. B.; Yates, B. S.; Breed, C. S.; Williams, E. S.; Brooks, B. W. Global Assessment of Bisphenol A in the Environment: Review and Analysis of Its Occurrence and Bioaccumulation. Dose-Response 2015, 13, 1-29.

(17) Zellnitz, S.; Redlinger-Pohn, J. D.; Kappl, M.; Schroettner, H.; Urbanetz, N. A. Preparation and characterization of physically modified glass beads used as model carriers in dry powder inhalers. Int. J. Pharm. 2013, 447, 132-138.

(18) Attri, P.; Gaur, J.; Choi, S.; Kim, M.; Bhatia, R.; Kumar, N.; Park, J. H.; Cho, A. E.; Choi, E. H.; Lee, W. Interaction studies of carbon nanomaterials and plasma activated carbon nanomaterials solution with telomere binding protein. Sci. Rep. 2017, 7, No. 2636.

(19) Niesner, R.; Heintz, A. Diffusion coefficients of aromatics in aqueous solution. J. Chem. Eng. Data 2000, 45, 1121-1124.

(20) Akbar, U.; Aschenbrenner, C. D.; Harper, M. R.; Johnson, H. R.; Dordick, J. S.; Clark, D. S. Direct solubilization of enzyme aggregates with enhanced activity in nonaqueous media. Biotechnol. Bioeng. 2007, 96, 1030-1039.

(21) Takemori, S.; Furuya, E.; Suzuki, H.; Katagiri, M. Stabilization of enzyme activity by an organic solvent. Nature 1967, 215, 417-419.

(22) Fang, J.; Wu, K.; Liu, Q. M.; Yang, S. J.; Wen, S. Synthesis of Ndoped mesoporous carbons under different carbonization temperature and their application in supercapacitors. J. Porous Mater. 2018, 25, 503-509.

(23) Shan, C. S.; Yang, H. F.; Han, D. X.; Zhang, Q. X.; Ivaska, A.; Niu, L. Water-Soluble Graphene Covalently Functionalized by Biocompatible Poly-L-lysine. Langmuir 2009, 25, 12030-12033.

(24) Zhang, S. A.; Yang, K.; Feng, L. Z.; Liu, Z. In vitro and in vivo behaviors of dextran functionalized graphene. Carbon 2011, 49, 4040-4049.

(25) Lv, J.; Chang, H.; Wang, Y.; Wang, M. M.; Xiao, J. R.; Zhang, Q.; Cheng, Y. Y. Fluorination on polyethylenimine allows efficient 2D and 3D cell culture gene delivery. J. Mater. Chem. B 2015, 3, 642650

(26) Sharma, V. K.; Thomas, M.; Klibanov, A. M. Mechanistic studies on aggregation of polyethylenimine-DNA complexes and its prevention. Biotechnol. Bioeng. 2005, 90, 614-620.

(27) Zaks, A.; Klibanov, A. M. The Effect of Water on Enzyme Action in Organic Media. J. Biol. Chem. 1988, 263, 8017-8021.

(28) Hu, Y.; Han, W. F.; Huang, G. H.; Zhou, W. Y.; Yang, Z. H.; Wang, C. Y. Highly Stretchable, Mechanically Strong, Tough, and Self-Recoverable Nanocomposite Hydrogels by Introducing Strong 
Ionic Coordination Interactions. Macromol. Chem. Phys. 2016, 217, $2717-2725$.

(29) Keplinger, C.; Sun, J. Y.; Foo, C. C.; Rothemund, P.; Whitesides, G. M.; Suo, Z. G. Stretchable, Transparent, Ionic Conductors. Science 2013, 341, 984-987.

(30) Park, J. K.; Seo, S. K.; Cho, S.; Kim, H. S.; Lee, C. H. Characteristics of Sodium Polyacrylate/Nano-Sized Carbon Hydrogel for Biomedical Patch. J. Nanosci. Nanotechnol. 2018, 18, 1611-1614.

(31) Ma, Y. D.; Dong, J. L.; Bhattacharjee, S.; Wijeratne, S.; Bruening, M. L.; Baker, G. L. Increased Protein Sorption in Poly(acrylic acid)-Containing Films through Incorporation of Comb-Like Polymers and Film Adsorption at Low $\mathrm{pH}$ and High Ionic Strength. Langmuir 2013, 29, 2946-2954.

(32) Pelaz, B.; del Pino, P.; Maffre, P.; Hartmann, R.; Gallego, M.; Rivera-Fernandez, S.; de la Fuente, J. M.; Nienhaus, G. U.; Parak, W. J. Surface Functionalization of Nanoparticles with Polyethylene Glycol: Effects on Protein Adsorption and Cellular Uptake. ACS Nano 2015, 9, 6996-7008.

(33) Alcantar, N. A.; Aydil, E. S.; Israelachvili, J. N. Polyethylene glycol-coated biocompatible surfaces. J. Biomed. Mater. Res. 2000, 51, 343-351.

(34) Ung, V. Y. L.; Foshaug, R. R.; MacFarlane, S. M.; Churchill, T. A.; Doyle, J. S. G.; Sydora, B. C.; Fedorak, R. N. Oral Administration of Curcumin Emulsified in Carboxymethyl Cellulose Has a Potent Anti-inflammatory Effect in the IL-10 Gene-Deficient Mouse Model of IBD. Dig. Dis. Sci. 2010, 55, 1272-1277.

(35) Arola, S.; Tammelin, T.; Setala, H.; Tullila, A.; Linder, M. B. Immobilization-Stabilization of Proteins on Nanofibrillated Cellulose Derivatives and Their Bioactive Film Formation. Biomacromolecules 2012, 13, 594-603.

(36) Fu, X. W.; Wang, Y.; Zhong, W. H.; Cao, G. Z. A Multifunctional Protein Coating for Self-Assembled Porous Nanostructured Electrodes. ACS Omega 2017, 2, 1679-1686.

(37) Fiegel, V.; Harlepp, S.; Begin-Colin, S.; Begin, D.; Mertz, D. Design of Protein-Coated Carbon Nanotubes Loaded with Hydrophobic Drugs through Sacrificial Templating of Mesoporous Silica Shells. Chemistry 2018, 24, 4662-4670.

(38) Nakamura, S.; Kobayashi, K.; Kato, A. Role of Positive Charge of Lysozyme in the Excellent Emulsifying Properties of Maillard-Type Lysozyme Polysaccharide Conjugate. J. Agric. Food Chem. 1994, 42, 2688-2691.

(39) Phan, H. T. M.; Bartelt-Hunt, S.; Rodenhausen, K. B.; Schubert, M.; Bartz, J. C. Investigation of Bovine Serum Albumin (BSA) Attachment onto Self-Assembled Monolayers (SAMs) Using Combinatorial Quartz Crystal Microbalance with Dissipation (QCMD) and Spectroscopic Ellipsometry (SE). PLoS One 2015, 10, No. e0141282.

(40) Kubiak-Ossowska, K.; Jachimska, B.; Mulheran, P. A. How Negatively Charged Proteins Adsorb to Negatively Charged Surfaces: A Molecular Dynamics Study of BSA Adsorption on Silica. J. Phys. Chem. B 2016, 120, 10463-10468.

(41) Kazandjian, R. Z.; Klibanov, A. M. Regioselective Oxidation of Phenols Catalyzed by Polyphenol Oxidase in Chloroform. J. Am. Chem. Soc. 1985, 107, 5448-5450.

(42) Han, M. J.; Bie, H. M.; Nikles, D. E.; Warren, G. W. Aminequinone polyimide: A new high-temperature polymer and its use to protect iron against corrosion. J. Polym. Sci., Part A: Polym. Chem. 2000, 38, 2893-2899.

(43) Wu, L.; Lu, X.; Zhang, H.; Chen, J. Amino acid ionic liquid modified mesoporous carbon: a tailor-made nanostructure biosensing platform. ChemSusChem 2012, 5, 1918-1925.

(44) Deborde, M.; Rabouan, S.; Mazellier, P.; Duguet, J. P.; Legube, B. Oxidation of bisphenol A by ozone in aqueous solution. Water Res. 2008, 42, 4299-4308.

(45) Park, C. G.; Choi, E. S.; Jeon, H. W.; Lee, J. H.; Sung, B. W.; Cho, Y. H.; Ko, K. B. Effect of nitrate on the degradation of bisphenol A by $\mathrm{UV} / \mathrm{H}_{2} \mathrm{O}_{2}$ and ozone $/ \mathrm{H}_{2} \mathrm{O}_{2}$ oxidation in aqueous solution. Desalin. Water Treat. 2014, 52, 797-804.
(46) Yoshida, M.; Ono, H.; Mori, Y.; Chuda, Y.; Onishi, K. Oxidation of bisphenol A and related compounds. Biosci., Biotechnol., Biochem. 2001, 65, 1444-1446.

(47) Olmez-Hanci, T.; Arslan-Alaton, I.; Genc, B. Bisphenol A treatment by the hot persulfate process: Oxidation products and acute toxicity. J. Hazard. Mater. 2013, 263, 283-290.

(48) Burgos-Castillo, R. C.; Sirés, I.; Sillanpää, M.; Brillas, E. Application of electrochemical advanced oxidation to bisphenol A degradation in water. Effect of sulfate and chloride ions. Chemosphere 2018, 194, 812-820.

(49) Ng, J. W.; Wang, X. P.; Sun, D. D. One-pot hydrothermal synthesis of a hierarchical nanofungus-like anatase $\mathrm{TiO} 2$ thin film for photocatalytic oxidation of bisphenol A. Appl. Catal., B 2011, 110, $260-272$. 